\title{
Comparison of gadolinium dose and acquisition time for late gadolinium enhancement at $3.0 \mathrm{~T}$
}

\author{
Adelina Doltra ${ }^{1 *}$, Alex Skorin $^{1}$, Bernhard Schnackenburg${ }^{2}$, Christoph Klein ${ }^{1}$, Eckart Fleck${ }^{1}$, Sebastian Kelle ${ }^{1}$ \\ From 17th Annual SCMR Scientific Sessions \\ New Orleans, LA, USA. 16-19 January 2014
}

\section{Background}

Although late gadolinium enhancement (LGE) is a widely used technique in daily clinical practice, the optimal contrast dose and time of acquisition at $3.0 \mathrm{~T}$ is unknown. Aim of our study was to compare different contrast doses and acquisition times for LGE imaging at 3.0 T.

\section{Methods}

34 patients with chronic myocardial infarction were randomized to $0.1(\mathrm{n}=12), 0.15(\mathrm{n}=11)$ and $0.2(\mathrm{n}=11) \mathrm{mmol} /$
Kg of gadolinium contrast (gadobenate dimeglumine MultiHance ${ }^{\circledR}$ ). T1-weighted inversion recovery gradient echo sequences were performed at 5, 10, 15 and 20 minutes post-administration of contrast in all groups, with an individually adapted trigger delay at every single time point. Signal-to-noise ratio (SNR) of the scar, contrast-to-noise ratio (CNR) of the scar in comparison to healthy myocardium and the percentage of enhanced area volume relative to the global myocardium were quantified. A 4-point score was used to assess image quality in all studies.

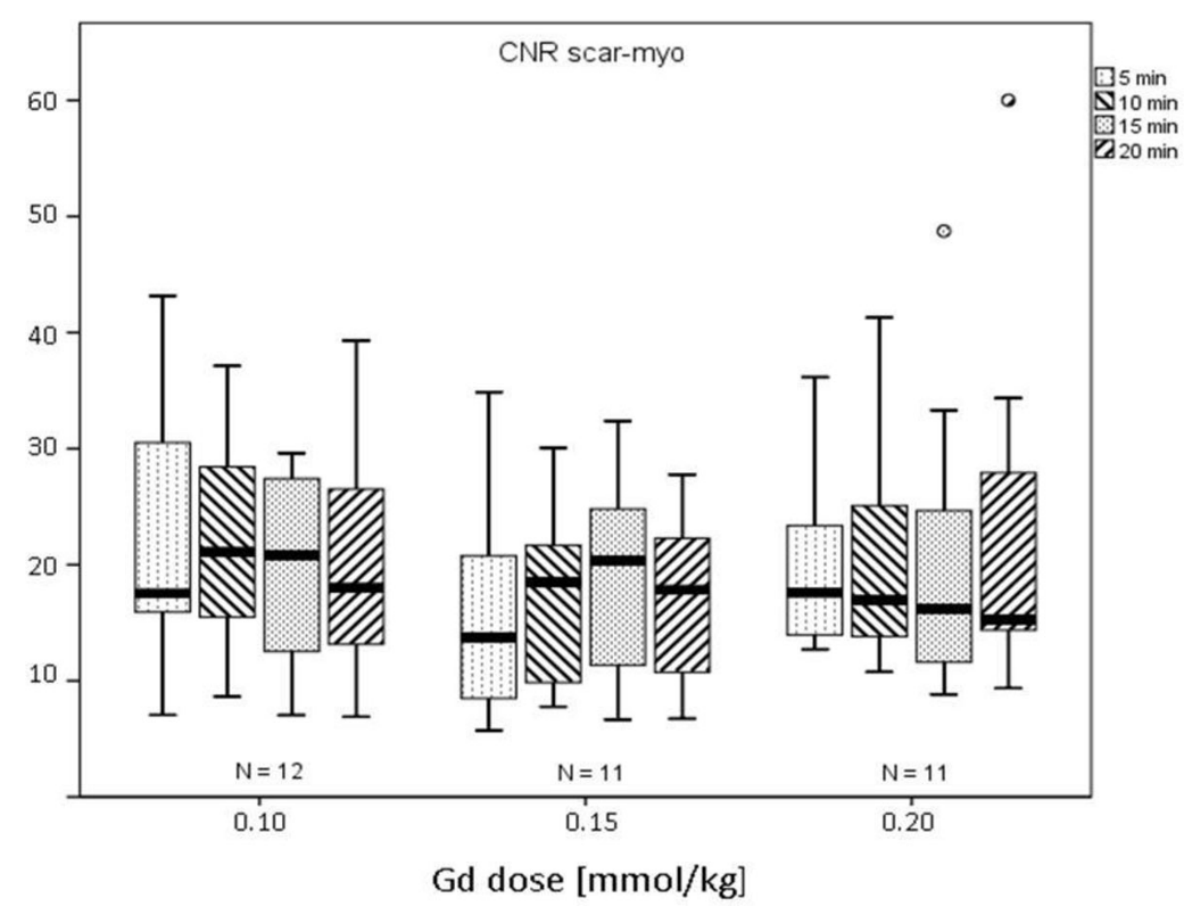

Figure 1 Contrast-to-noise ratio of the scar tissue compared to the non-enhanced myocardium at 3 doses and 4 different time-points.

${ }^{1}$ Cardiology, German Heart Institute Berlin, Berlin, Germany 

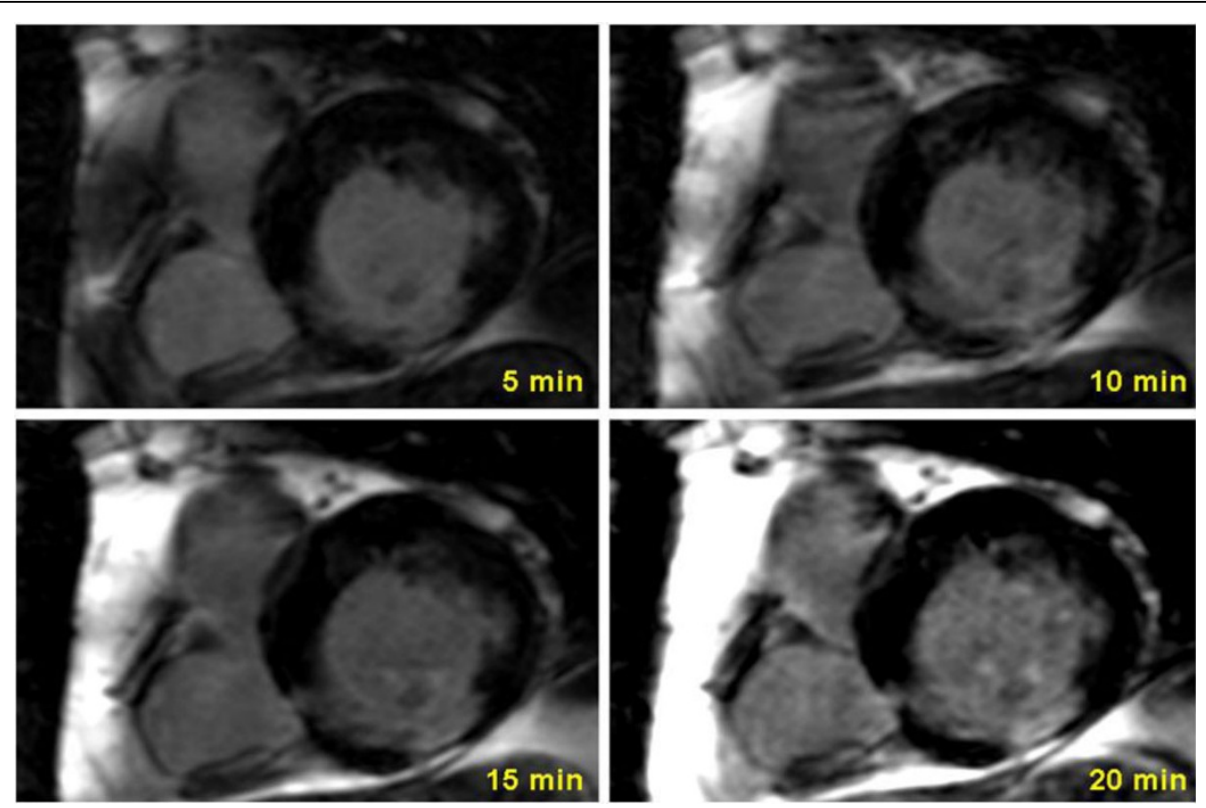

Figure 2 Short axis views of a patient with an infarction of the basal inferior wall acquired 5, 10, 15 and 20 min after the administration of $0.10 \mathrm{mmol} / \mathrm{kg} \mathrm{Gd}$.

\section{Results}

No differences were observed in SNR and CNR (see Figure 1), neither between the doses being evaluated nor between the different acquisition times. Regarding enhanced area volume, at $0.1 \mathrm{mmol} / \mathrm{kg}$ of Gd contrast, imaging at $5 \mathrm{~min}$ yielded lower enhanced area volumes in comparison to 15 and 20 minutes $(7.5 \pm 4.3 \mathrm{vs}$ $9 \pm 3.9$ vs $9.5 \pm 5.4, \mathrm{p}=0.03$ and $\mathrm{p}=0.02$, respectively) (Figure 2). No significant differences between imaging times were observed at 0.15 and $0.2 \mathrm{mmol} / \mathrm{kg}$. Finally, when analyzing image quality at $0.20 \mathrm{mmol} / \mathrm{kg} \mathrm{Gd}$ significant changes were observed between 5 and 15 $\min (2.6 \pm 0.5$ vs $3.2 \pm 0.8, \mathrm{p}=0.014), 5$ and $20 \mathrm{~min}$ ( $2.6 \pm 0.5$ vs $3,2.6 \pm 0.5$ vs $0.8, p=0.046)$ as well as 10 and $15 \mathrm{~min}(2.7 \pm 0.5$ vs $3.2 \pm 0.8, \mathrm{p}=0.025)$, with no significant differences in the remaining imaging times and doses.

\section{Conclusions}

In LGE imaging at 3.0T low doses of gadolinium and early acquisitions perform equally well in terms of SNR and CNR, although a trend towards poorer image quality with early acquisitions is noted. When using lower contrast doses, early acquisition is associated with lower enhanced area volumes. As a consequence, late acquisition is preferable. Studies with sufficient diagnostic quality could be obtained using shorter protocols with low contrast doses.

\section{Funding}

None.

\section{Authors' details}

${ }^{1}$ Cardiology, German Heart Institute Berlin, Berlin, Germany. ${ }^{2}$ Philips Healthcare Systems, Hamburg, Germany.

Published: 16 January 2014

doi:10.1186/1532-429X-16-S1-094

Cite this article as: Doltra et al:: Comparison of gadolinium dose and acquisition time for late gadolinium enhancement at $3.0 \mathrm{~T}$. Journal of Cardiovascular Magnetic Resonance 2014 16(Suppl 1):094.

\section{Submit your next manuscript to BioMed Central and take full advantage of: \\ - Convenient online submission \\ - Thorough peer review \\ - No space constraints or color figure charges \\ - Immediate publication on acceptance \\ - Inclusion in PubMed, CAS, Scopus and Google Scholar \\ - Research which is freely available for redistribution

